\title{
High-cycle fatigue behavior of beta-titanium orthodontic wires
}

\author{
Takashi MURAKAMI', Masahiro IIJIMA², Takeshi MUGURUMA², Fumiaki YANO'1, Isao KAWASHIMA³ \\ and Itaru MIZOGUCHI
}

\author{
${ }^{1}$ Analytical Applications Department, Kyoto Application Development Center, Shimadzu Corporation, 1, Nishinokyo-Kuwabaracho, Nakagyo-ku, \\ Kyoto 604-1094, Japan \\ ${ }^{2}$ Division of Orthodontics and Dentofacial Orthopedics, Department of Oral Growth and Development, School of Dentistry, Health Sciences University \\ of Hokkaido, 1757 Kanazawa, Ishikari-Tobetsu, Hokkaido 061-0293, Japan \\ ${ }^{3}$ Department of Biomaterilas, School of Dentistry, Ohu University, Aza Sankakudo, Tomita, Koriyama, Fukushima 963-8611, Japan \\ Corresponding author, Masahiro IIJIMA; E-mail: iijima@hoku-iryo-u.ac.jp
}

\begin{abstract}
This study investigated high-cycle fatigue behavior in three $\beta$-Ti wires (TMA, Resolve, Gummetal). Fatigue was evaluated using a static three-point bending test and a high-cycle fatigue test with a three-point bending mode. The surfaces of fractured wires were observed with scanning electron microscopy, and the post-fatigue crystal structures were determined by micro-X-ray diffraction. The Gummetal wire exhibited the lowest elastic modulus, bending strength and fatigue limit, and exhibited the highest resilience of the three types of wire studied. However, no difference in the number of cycles to failure was observed among the three types of wire. The fatigue crack propagation and rapid propagation regions of all wires contained single-phase $\beta$-Ti. The elastic modulus and bending strength influenced the fatigue limit, although these properties did not affect the number of cycles to fracture. The three types of $\beta$-Ti wires exhibited similar risks of wire fracture.
\end{abstract}

Keywords: Orthodontic wire, Beta-titanium, Fatigue

\section{INTRODUCTION}

Titanium (Ti) alloys are increasingly used as biomaterials due to their excellent mechanical properties and superior biocompatibility. The two crystal structures of Ti are commonly called the alpha $(\alpha)$ and beta $(\beta)$ phases. Alpha-phase titanium $(\alpha-\mathrm{Ti})$ is any pure or alloyed hexagonal $\mathrm{Ti}$, while beta-phase $\mathrm{Ti}(\beta-\mathrm{Ti})$ is any pure or alloyed cubic $\mathrm{Ti}^{1}$. $\alpha$-Ti alloys have a relatively high elastic modulus, exhibit lower formability ${ }^{1)}$, and are common in dental implants. A $\beta$-Ti alloy (also referred to as $\beta$-III in engineering materials nomenclature) was first suggested for orthodontic wire use by Burstone and Goldberg ${ }^{2)}$. $\beta$-Ti is one of four common wire types [nickeltitanium (Ni-Ti), $\beta$-Ti, stainless steel, cobalt-chromiumnickel (Co-Cr-Ni)] used for fixed appliances because of its intermediate force delivery, biocompatibility, $\mathrm{Ni}$-free composition, thin surface $\mathrm{TiO}_{2}$ passivation layer, high springback, and excellent formability attributable to many slip systems available for dislocation motions in the body-centered cubic (bcc) structure ${ }^{2-4)}$. On the other hand, formation or inclusion of omega-phase $\mathrm{Ti}(\omega-\mathrm{Ti})$ in $\beta$-Ti alloys causes embrittlement and reduced ductility, although $\omega$-Ti can be used to strengthen alloys ${ }^{5,6)}$.

A major clinical drawback to the use of $\beta$-Ti alloys in orthodontic wires is their fracture and resistance to sliding (high friction) ${ }^{4}$. The fracture of $\beta$-Ti alloy orthodontic wires is caused by fatigue damage due to multiple rebending, degradation under stress in the oral environment and hydrogen embrittlement using

Color figures can be viewed in the online issue, which is available at J-STAGE.

Received Jan 14, 2014: Accepted Oct 17, 2014

doi:10.4012/dmj.2014-012 JOI JST.JSTAGE/dmj/2014-012 fluoride-containing products ${ }^{4,7}$. The fatigue performance is an important mechanical performance characteristic of biomaterials, because they are typically used under cyclic loading ${ }^{6,8,9)}$. Although many investigators have examined the static bending and tension properties of orthodontic $\beta$-Ti wires ${ }^{2-4,10,11)}$, the American National Standard/American Dental Association Specification (ANSI/ADA) No. 32 for orthodontic wires ${ }^{12)}$ does not describe fatigue testing or the cycle fatigue performance of $\beta$-Ti wires. Thus, better understating of the high-cycle fatigue behavior of $\beta$-Ti would provide additional insight into the failure mechanisms of $\beta$-Ti orthodontic wires and would be more clinically relevant than the currently available information on static mechanical behavior.

This study investigated the high-cycle fatigue behavior of three different commercially available $\beta$-Ti orthodontic wires, the first study to do so to the best of our knowledge. We expected that high-cycle fatigue behavior of $\beta$-Ti wires would differ from their known static mechanical properties.

\section{MATERIALS AND METHODS}

\section{Materials}

Three $\beta$-Ti wires, TMA (Ormco, Glendora, California, USA), Resolve (3M Unitek, Monrovia, California, USA) and Gummetal (Rocky Mountain Morita Corporation, Tokyo, Japan), were selected. The cross-sectional dimensions for the wires were $0.016 \times 0.022$ inches for TMA and Resolve, and $0.017 \times 0.025$ inches for Gummetal. The nominal wire compositions were confirmed by X-ray fluorescence spectrometry (EDX-720, Shimadzu, 
Kyoto, Japan) and are summarized in Table 1. The TMA and Resolve wires had similar compositions: Ti alloy containing approximately $13-14 \% \mathrm{Mo}, 6 \% \mathrm{Zr}$, and $5 \%$ Sn; the Gummetal wire was a $\mathrm{Ti}$ alloy with approximately $36 \% \mathrm{Nb}$ and small amounts of $\mathrm{Zr}$, Mo, Ta, and Sn.

Static bending and high-cycle fatigue tests

A static three-point bending test was carried out on the three brand wires $(n=5)$ using a universal testing machine with a 50-N load cell (AG-50NXplus, Shimadzu) at room temperature $\left(25^{\circ} \mathrm{C}\right)$. The tips of the supports and the striker in the three-point bending test had a curvature radius of $0.1 \mathrm{~mm}$, and each support span was $10 \mathrm{~mm}$. Each wire was loaded to a strain of $8.5 \%$ at a rate of $5 \mathrm{~mm} / \mathrm{min}$. Loading to a strain of $8.5 \%$ corresponded approximately to double maximum bending strain of each wire. The strain is calculated by using the following formula:

$$
\varepsilon=\left(6 T / L^{2}\right) \Delta l
$$

where $T$ is thickness of wire, $L$ is the support span, and $\Delta l$ is displacement of actuator of testing machine.

A cyclic three-point bending mode with a span length of $10 \mathrm{~mm}$ was used for the fatigue testing. The maximum stress and the amplitude for the fatigue test were determined using bend strength values obtained from a static bending test, and are shown in Table 2. Additionally, schematic illustration of fatigue testing is shown in Fig. 1. The fatigue tests were carried out using an electromagnetic force micro-material tester with a
100-N load cell (MMT-101N, Shimadzu) at a repetition frequency of $20 \mathrm{~Hz}$.

\section{Scanning electron microscopy (SEM) and micro-X-ray} diffraction (micro-XRD)

After high-cycle fatigue testing, fractured wires (without sputter-coating of the surfaces) were examined by SEM (S-3500N, Hitachi, Tokyo, Japan) operating at $15 \mathrm{kV}$. The fracture surfaces were then analyzed by microXRD (Rint-2500, Rigaku Corp., Tokyo, Japan). Micro-

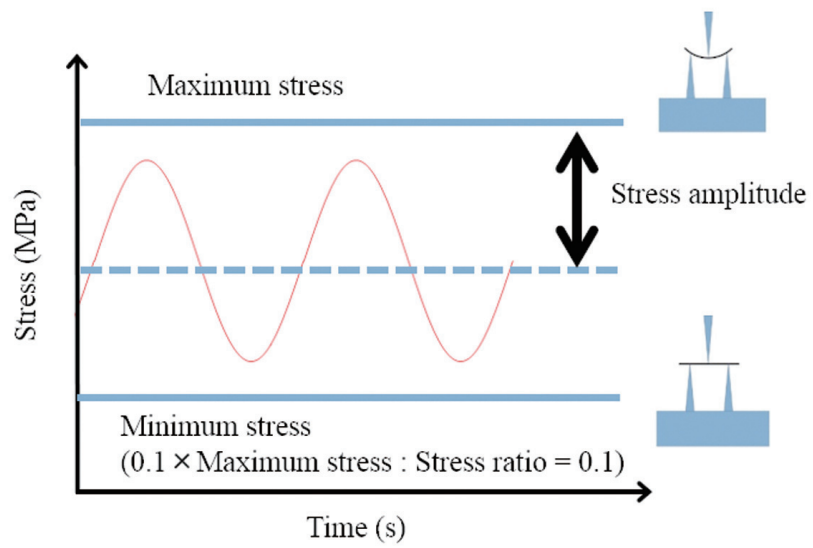

Fig. 1 Schematic illustration of fatigue testing.

Table 1 Composition of the beta-titanium wires (wt.\%)*

\begin{tabular}{lcccccc}
\hline & $\mathrm{Ti}$ & $\mathrm{Zr}$ & $\mathrm{Nb}$ & $\mathrm{Mo}$ & $\mathrm{Ta}$ & $\mathrm{Sn}$ \\
\hline TMA & 75.2 & 5.9 & - & 14.1 & 12.7 & - \\
Resolve & 76.6 & 5.8 & - & 0.2 & 2.6 & 4.8 \\
Gummetal & 58.4 & 3.0 & 35.7 & 0.1 \\
\hline
\end{tabular}

Ti, Titanium; Zr, Zirconium; Nb, Niobium; Mo, Molybdenum; Ta, Tantalum; Sn, Tin.

*Determined by X-ray fluorescence analysis.

Table 2 Test condition of high-cycle fatigue test

\begin{tabular}{|c|c|c|c|c|c|c|c|c|c|c|c|}
\hline \multicolumn{4}{|c|}{ TMA } & \multicolumn{4}{|c|}{ Resolve } & \multicolumn{4}{|c|}{ Gummetal } \\
\hline \multicolumn{2}{|c|}{$\begin{array}{l}\text { Maximum } \\
\text { stress }\end{array}$} & \multirow{2}{*}{$\begin{array}{l}\text { Stress } \\
\text { ratio }\end{array}$} & \multirow{2}{*}{$\begin{array}{c}\text { Stress } \\
\text { amplitude } \\
(\mathrm{MPa})\end{array}$} & \multicolumn{2}{|c|}{$\begin{array}{l}\text { Maximum } \\
\text { stress }\end{array}$} & \multirow{2}{*}{$\begin{array}{l}\text { Stress } \\
\text { ratio }\end{array}$} & \multirow{2}{*}{$\begin{array}{c}\text { Stress } \\
\text { amplitude } \\
(\mathrm{MPa})\end{array}$} & \multicolumn{2}{|c|}{$\begin{array}{l}\text { Maximum } \\
\text { stress }\end{array}$} & \multirow{2}{*}{$\begin{array}{l}\text { Stress } \\
\text { ratio }\end{array}$} & \multirow{2}{*}{$\begin{array}{c}\text { Stress } \\
\text { amplitude } \\
(\mathrm{MPa})\end{array}$} \\
\hline (MPa) & (gf) & & & (MPa) & (gf) & & & (MPa) & (gf) & & \\
\hline 1,300 & $1,136.6$ & 0.10 & 585 & 1,300 & $1,136.6$ & 0.10 & 585 & 1,000 & $1,179.0$ & 0.10 & 450 \\
\hline 1,200 & $1,049.2$ & 0.10 & 540 & 1,200 & $1,049.2$ & 0.10 & 540 & 900 & $1,061.1$ & 0.10 & 405 \\
\hline 1,100 & 961.7 & 0.10 & 495 & 1,100 & 961.7 & 0.10 & 495 & 800 & 943.2 & 0.10 & 360 \\
\hline 1,000 & 874.3 & 0.10 & 450 & 1,000 & 874.3 & 0.10 & 450 & 700 & 825.3 & 0.10 & 315 \\
\hline 900 & 786.9 & 0.10 & 405 & 975 & 852.5 & 0.10 & 439 & 690 & 813.5 & 0.10 & 311 \\
\hline 800 & 699.5 & 0.10 & 360 & - & - & - & - & 675 & 795.8 & 0.10 & 304 \\
\hline
\end{tabular}


XRD analyses were performed with $\mathrm{Cu} \mathrm{K} \alpha$ radiation at $40 \mathrm{kV}$ and a tube current of $300 \mathrm{~mA}$. The specimens were oscillated from $+22^{\circ}$ to $+28^{\circ}$ about the $\omega$-axis and rotated from $-60^{\circ}$ to $+60^{\circ}$ about the $\varphi$-axis to minimize the influence of a preferred orientation. The locations of these axes are shown in previous publications that describe the micro-XRD technique ${ }^{13)}$. A 50- $\mu$ m-diameter collimator was used to establish the dimensions of the analysis area. The diffracted X-rays were detected by a position-sensitive proportional counter (PSPC). The measurement time for scanning over the diffraction

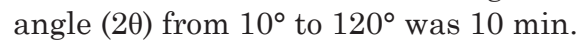

\section{Statistical analysis}

Statistical analysis was performed using PASW Statistics (version 18.0J for Windows, IBM, Armonk, NY, USA). The data for the bending elastic modulus, bending strength, and elastic energy (Resilience) of the three types of $\beta$-Ti wires were not normally distributed (Levene test). A Kruskal-Wallis test was applied to determine whether significant differences existed among the groups. The Mann-Whitney U test was then used for two independent groups, and the Bonferroni correction was applied $(p<0.0167)$.

\section{RESULTS}

Representative stress-strain curves and stress $v s$. number of cycles ( $S-N$ curves) are show in Figs. 2 (a) and (b); the bending elastic modulus, bending strength, fatigue limits, and resilience are summarized in Table 3. According to the Kruskal-Wallis test and the MannWhitney U test, the Resolve wire exhibited significantly higher mean elastic modulus and bending strength than the Gummetal wire did, and the values for both were significantly lower than those of the TMA wire. The Gummetal wire exhibited significantly higher mean resilience than the other two wires. The fatigue strength at approximately $10^{4}$ cycles in the Gummetal wire was lower than those of the TMA and Resolve wires, although there was no difference in the number of cycles to failure among the three types of $\beta$-Ti wires (The values shown in the shadow area). The fatigue limit of the three $\beta$-Ti wires ranged from $304 \mathrm{MPa}$ for Gummetal to $439 \mathrm{MPa}$ for Resolve.

Figure 3 contains representative stress-stroke curves of the three types of $\beta$-Ti wires at 100 cycles as well as at the cycles just prior to the fatigue limit. The stress-stroke curves of the Resolve wire (maximum stress: $900 \mathrm{MPa}$, stress amplitude: $405 \mathrm{MPa}$ ) and the Gummetal wire (maximum stress: $690 \mathrm{MPa}$, stress amplitude: $311 \mathrm{MPa}$ ) for cycles just prior to the fatigue limit exhibited some hysteresis, which was not apparent in the the TMA wire.

Figure 4 contains representative SEM images of the fracture surfaces of the three types of $\beta$-Ti wires examined in this study (TMA, maximum stress: $900 \mathrm{MPa}$, stress amplitude $405 \mathrm{MPa}$; Resolve, maximum stress: 1,000 $\mathrm{MPa}$, stress amplitude $450 \mathrm{MPa}$; Gummetal, maximum stress: $690 \mathrm{MPa}$, stress amplitude $311 \mathrm{MPa})$. The fracture
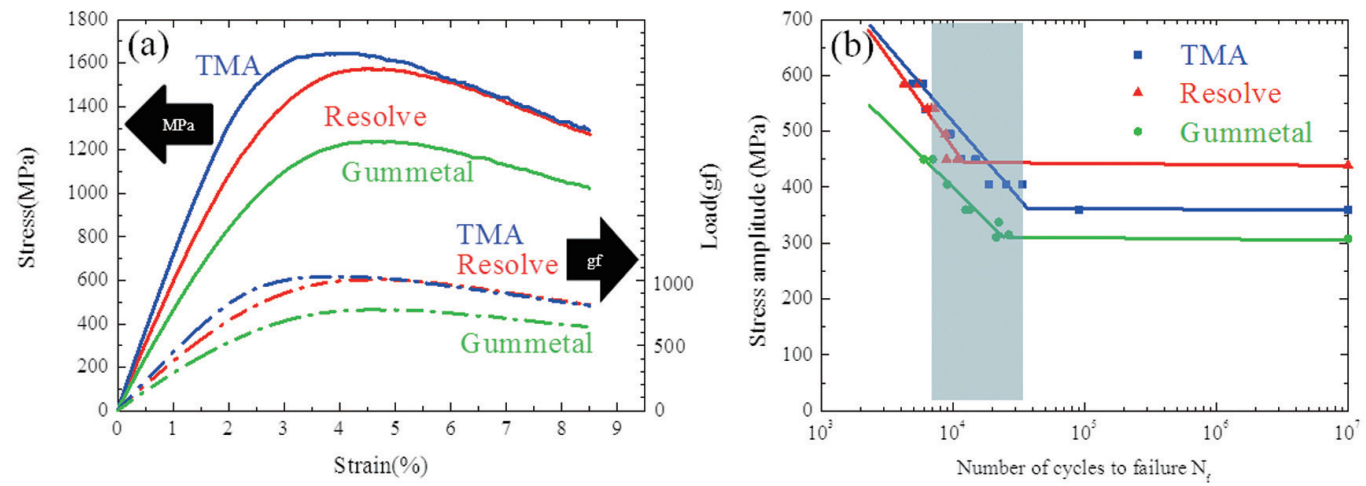

Fig. 2 Representative (a) stress-strain curves and (b) S-N curves of three $\beta$-Ti wires.

Table 3 Mechanical properties (Elastic modulus, Bending strength, Fatigue limit, Resilience) of three beta-titanium wires

\begin{tabular}{lcccc}
\hline & TMA & Resolve & Gummetal & $p$ value \\
\hline Bending elastic modulus (MPa) & $71,813^{\mathrm{a}}$ & $58,382^{\mathrm{b}}$ & $44,540^{\mathrm{c}}$ & 0.002 \\
Bending strength (MPa) & $1,660^{\mathrm{a}}$ & $1,576^{\mathrm{b}}$ & $1,241^{\mathrm{c}}$ & 0.002 \\
Fatigue limit (MPa) & 360 & 439 & 304 & - \\
Resilience (J) & $0.00067^{\mathrm{a}}$ & $0.0007^{\mathrm{a}}$ & $0.00086^{\mathrm{b}}$ & 0.004 \\
\hline
\end{tabular}

Identical letters indicate that mean values were not significantly different. 

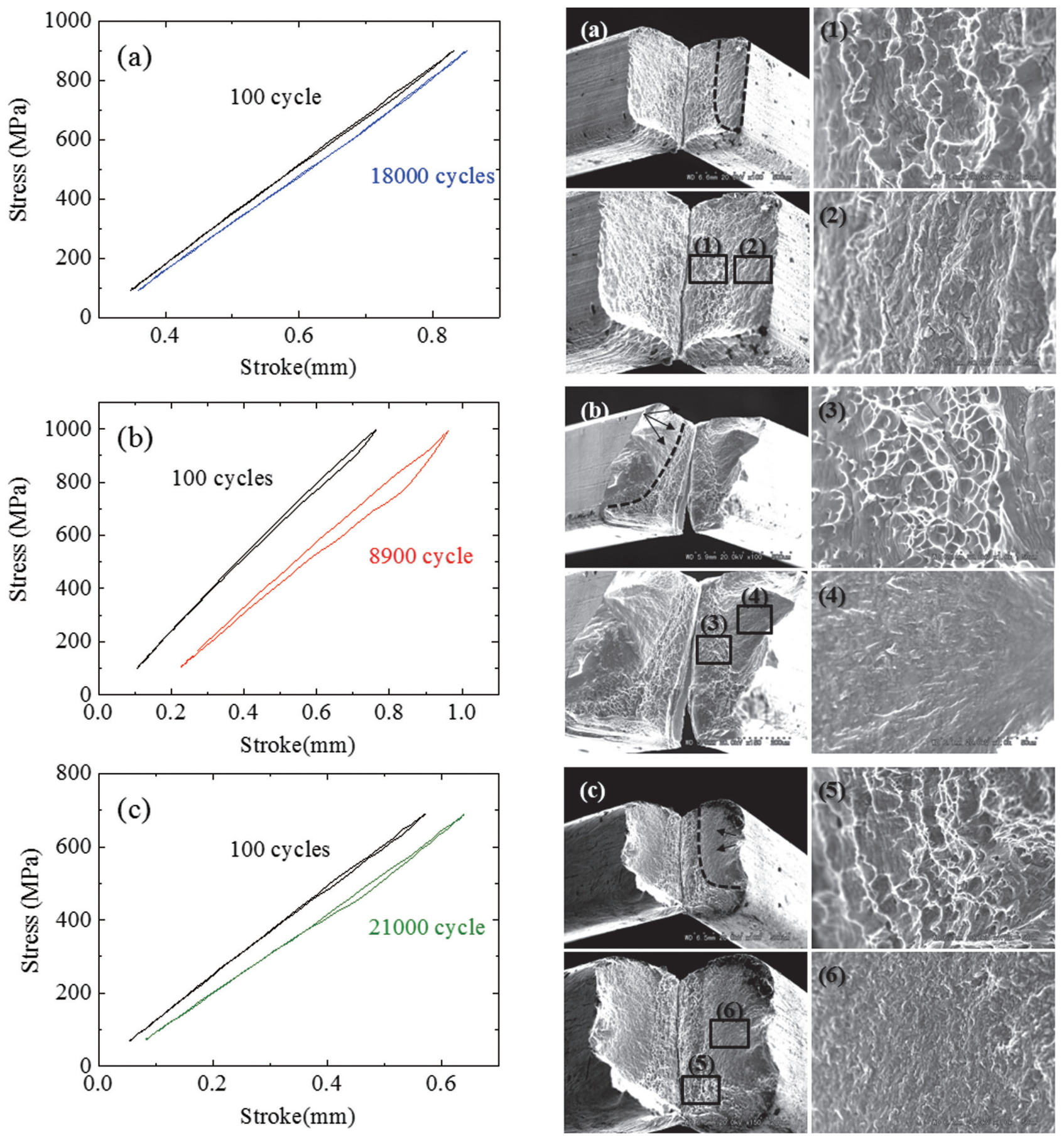

Fig. 3 Representative stress-stroke curves of three $\beta$-Ti wires.

(a) TMA, maximum stress: $900 \mathrm{MPa}$, stress amplitude: $405 \mathrm{MPa}$; (b) Resolve, maximum stress: 1,000 $\mathrm{MPa}$, stress amplitude: $450 \mathrm{MPa}$ (c) Gummetal, maximum stress: $690 \mathrm{MPa}$, stress amplitude: $311 \mathrm{MPa}$.

Fig. 4 Representative SEM images of fractured surfaces on three $\beta$-Ti wires.

(a) TMA, maximum stress: $900 \mathrm{MPa}$, stress amplitude: $405 \mathrm{MPa}$; (b) Resolve, maximum stress: 1,000 $\mathrm{MPa}$, stress amplitude: $450 \mathrm{MPa}$; (c) Gummetal, maximum stress: $690 \mathrm{MPa}$, stress amplitude: $311 \mathrm{MPa}$. (1), (3) and (5): rapid propagation region; (2), (4) and (6): fatigue crack propagation region. The areas of crack initiations are shown by the arrows. 

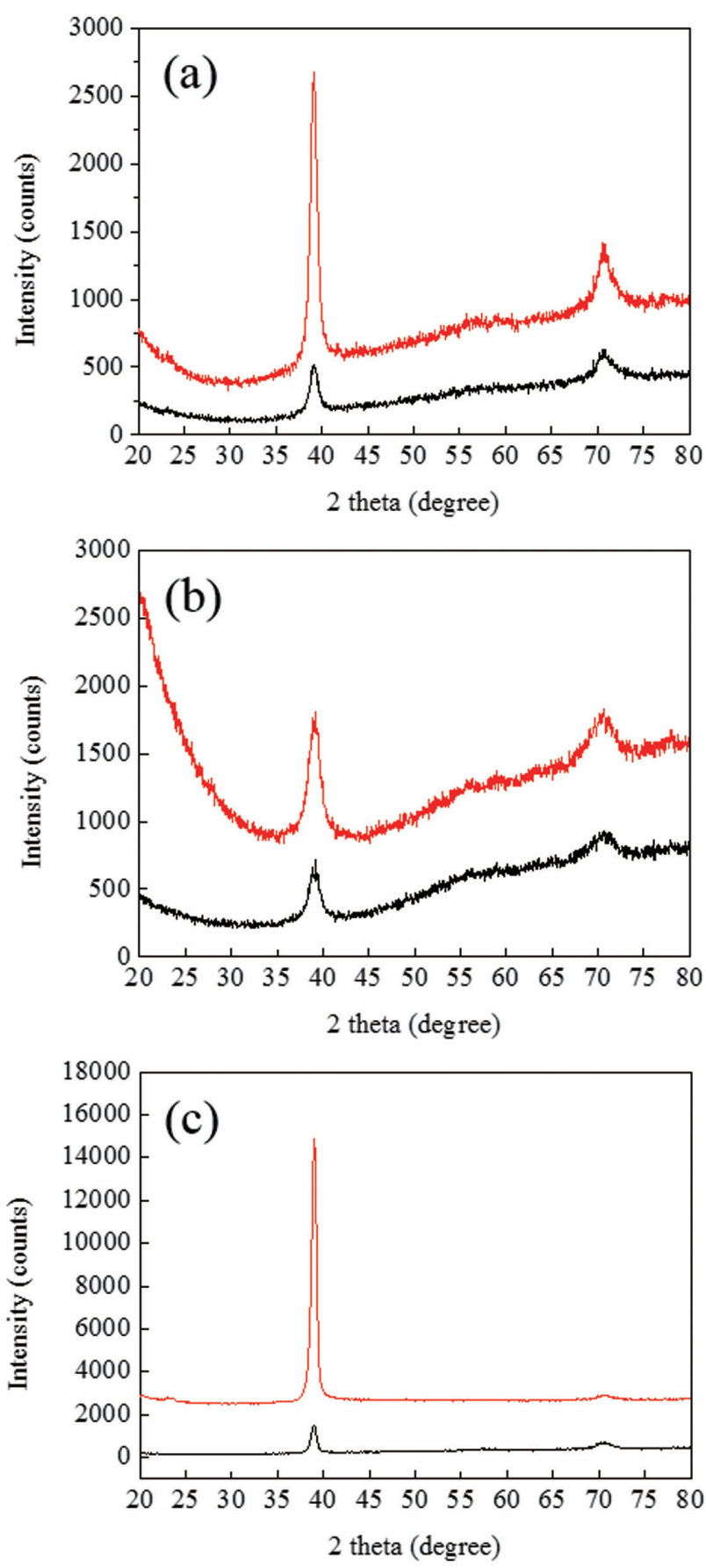

Fig. 5 Representative micro-XRD spectra of three $\beta$-Ti wires.

(a) TMA, maximum stress: $900 \mathrm{MPa}$, stress amplitude: $405 \mathrm{MPa}$; (b) Resolve, maximum stress: 1,000 $\mathrm{MPa}$, stress amplitude: $450 \mathrm{MPa}$; (c) Gummetal, maximum stress: $690 \mathrm{MPa}$, stress amplitude: $311 \mathrm{MPa}$. The spectra of upper were obtained from the fatigue crack propagation regions and the spectra of lower were obtained from the rapid propagation regions. surfaces of these wires comprised two morphologically distinct regions: a fatigue crack propagation region (outer bending region) [Figs. 4-(2), (4) and (6)] associated with tension stress, and a rapid propagation region (interior bending region) [Figs. 3-(1), (3), and (5)] associated with compression stress. This phenomenon has been evaluated for various materials by characterization of the relationship between the crack growth fatigue cycle, $\mathrm{da} / \mathrm{dN}$, and the stress intensity factor range, $\Delta \mathrm{K}^{14,15)}$. The areas of crack initiations of the Resolve and Gummetal are shown by the arrows. Fatigue striations were clearly observed in the rapid propagation regions, in addition to substantially equiaxed dimple structures of various sizes. The rapid propagation regions of the Resolve and Gummetal wires exhibited relatively flat surfaces.

Figure 5 contains representative micro-XRD spectra of the three types of $\beta$-Ti wires. The spectra of upper were obtained from the fatigue crack propagation regions and the spectra of lower were obtained from the rapid propagation regions. Both the fatigue crack propagation and the rapid propagation regions contained only peaks associated with $\beta$-Ti. The spectra of the TMA and Resolve wires exhibited relatively broad peaks compared to the Gummetal wires, attributable to heavy cold-working during wire processing by their respective manufacturers.

\section{DISCUSSION}

Orthodontic wires have been investigated using various mechanical testing methods, such as the tension test ${ }^{11,16)}$, three-point bending test ${ }^{4,11,16,17)}$ and nanoindentation test $^{11,18)}$. The mean bending elastic modulus of the TMA wire measured in this study $(72 \mathrm{GPa})$ was similar to those previously reported in the literature ${ }^{4)}$ for the same product (62-69 GPa). However, the elastic modulus of the Resolve wire $(73 \mathrm{GPa})$ reported by Iijima et al. ${ }^{11)}$ which was based on three-point bending, was higher than the value obtained in this study (58 GPa). The difference in the measured values for the same material is attributable to lot-to-lot product variation and/or different design of the three-point bending systems.

Orthodontic force is influenced by the elastic modulus and the average values of elastic modulus obtained in the present study varied from 44,540 $\mathrm{MPa}$ for Gummetal to $71,813 \mathrm{MPa}$ for TMA. A previous systematic review article showed that human studies dealing with the relation between force magnitude and rate of tooth movement used various initial forces and that there is no evidence-based force level for the optimal efficiency in clinical orthodontics ${ }^{19)}$. Therefore, orthodontic tooth movement is influenced by not only orthodontic force level but the biological tissue reaction and resistance to sliding between brackets and archwire. In this study, the fatigue limit depended on the elastic modulus and bending strength. The Gummetal wire exhibited the lowest bending elastic modulus, bending strength, and fatigue limit, suggesting that it demonstrates continuously light orthodontic force compared with the other types of wire evaluated. On the 
other hand, resilience is the area under the stress-strain curve out to the proportional limit. It represents the energy storage capacity of the wire, which is a combination of strength and springiness ${ }^{20)}$. Since the Gummetal wire exhibited significantly higher mean resilience than the other two wires, this wire may represent ability to achieve wide range tooth movement.

In the current study, the fatigue limit of the three types of $\beta$-Ti wires ranged from $304 \mathrm{MPa}$ for Gummetal to $439 \mathrm{MPa}$ for Resolve. These values are much lower than that reported by Niinomi ${ }^{6}$ ) for a cold rolled plate of Ti$29 \mathrm{Nb}-13 \mathrm{Ta}-4.6 \mathrm{Zr}$ alloy with a $\beta$-Ti phase (approximately $620 \mathrm{MPa}$ ), although Niinomi used a different fatigue mode (tension-tension). In addition, the number of cycles to failure for specimens evaluated in the present study was smaller than that reported by Niinomi'), possibly because alloys with different compositions were used, or because changes in the surface morphology and microstructure attributable to the wire manufacturing process influenced the fatigue behavior. On the other hand, there was no difference in the number of cycles to failure among the three types of $\beta$-Ti wires evaluated in this study under the same deformation conditions, suggesting that they all pose similar levels of fracture risk during clinical use. The TMA wire exhibited a high-angle $\mathrm{S}-\mathrm{N}$ curve compared to the Resolve wire, suggesting that the number of cycles to failure for the TMA and Resolve wires would coincide if the stress amplitude of the cycle fatigue test were increased. Just prior to failure in the cyclic fatigue test, the Resolve wire exhibited wider hysteresis in the stress-stroke curves, while the TMA wire did not exhibit hysteresis. Because the hysteresis to fatigue load is related to the heat energy lost within the material, the extent of hysteresis indicates the crack propagation progress. Consequently, fatigue destruction of the Resolve wire was relatively slow, while fatigue destruction of the TMA wire was rapid after a specific number of stress cycles was exceeded. The SEM images obtained in the present study showed that the crevasses on the surfaces of the Resolve and Gummetal wires were not formed linearly; instead, the cracks occurred from multiple locations, and fan-like fatigue crack propagation originated from scratches on the wire surfaces [Figs. 4(b) and (c)]. On the other hand, the crevasses on the surface of the TMA wire were relatively linear, which was attributed to the scratch and void surface morphology associated with the manufacturing process.

Previous studies demonstrated that the existence of $\omega$-Ti in $\beta$-Ti alloys causes embrittlement by decreasing ductility, although $\omega$-Ti can be used for strengthening ${ }^{5,6}$. Micro-XRD analysis in the present study confirmed that only single-phase $\beta$-Ti was observed in both the fatigue crack propagation and rapid propagation regions of all $\beta$-Ti specimens evaluated. Consequently, the fatigue characteristics observed in this study were not influenced by the existence of $\omega$-Ti in the structures. The spectra of the Gummetal wire exhibited relatively sharp peaks, possibly due to less cold-working or heat treatment during wire manufacturing. These same differences in the manufacturing process may also have contributed to the low bending elastic modulus and fatigue limit of the Gummetal wire compared to other two types of wire.

\section{CONCLUSION}

The bending elastic modulus and bending strength influenced the cyclic fatigue limit of $\beta$-Ti, although they did not affect the number of cycles to fracture. Consequently, the three types of $\beta$-Ti wires evaluated in this study pose similar risk of wire fracture under similar deformation conditions. The TMA wire exhibited rapid crack propagation during cyclic deformation, while the Resolve and Gummetal wires exhibited relatively slow crack propagation.

\section{REFERENCES}

1) Donachie MJ, Jr. A primer on titanium and its alloys. In: Donachie MJ, editor. Titanium: A Technical Guide. 2nd ed. Metals Park, Ohio: ASM International; 2000. p. 13-24.

2) Burstone CJ, Goldberg AJ. Beta titanium: A new orthodontic alloy. Am J Orthod 1980; 77: 121-132.

3) Kusy RP. A review of contemporary archwires: Their properties and characteristics. Angle Orthod 1997; 67: 197208.

4) Brantley WA. Orthodontic wires. In: Brantley WA, Eliades T, editors. Orthodontic materials: scientific and clinical aspects. Stuttgart: Thieme; 2001. p. 77-103.

5) Williams JC, Hickman BS, Marcus HL. The effect of omega phase on the mechanical properties of titanium alloys. Metall Trans 1971; 2: 1913-1919.

6) Niinomi M. Fatigue performance and cyto-toxicity of low rigidity titanium alloy, Ti-29Nb-13Ta-4.6Zr. Biomaterials 2003; 24: 2673-2683.

7) Kaneko K, Yokoyama K, Moriyama K, Asaoka K, Sakai J, Nagumo M. Delayed fracture of beta titanium orthodontic wire in fluoride aqueous solutions. Biomaterials 2003; 24: 2113-2120.

8) Kappert PF, Kelly JR. Cyclic fatigue testing of denture teeth for bulk. Dent Mater 2013; 29: 1012-1019.

9) Lin CW, Ju CP, Chern Lin JH. A comparison of the fatigue behavior of cast Ti-7.5Mo with c.p. titanium, Ti-6Al-4V and Ti-13Nb-13Zr alloys. Biomaterials 2005; 26: 2899-2907.

10) Kapila S, Sachdeva R. Mechanical properties and clinical applications of orthodontic wires. Am J Orthod Dentofacial Orthop 1989; 96: 100-109.

11) Iijima $M$, Muguruma $T$, Brantley WA, Mizoguchi $I$. Comparisons of nanoindentation, 3-point bending, and tension tests for orthodontic wires. Am J Orthod Dentofacial Orthop 2011; 140: 65-71.

12) ANSI/ADA Standard No. 32 -Orthodontic wires.

13) Iijima M, Ohno H, Kawashima I, Endo K, Brantley WA, Mizoguchi I. Micro X-ray diffraction study of superelastic nickel-titanium orthodontic wires at different temperatures and stresses. Biomaterials 2002; 23: 1769-1774.

14) Dubey S, Soboyejo ABO, Soboyejo WO. An investigation of the effects of stress ratio and crack closure on the micromechanism of fatigue crack growth in Ti-6Al-4V. Acta Mater 1997; 45: 2777-2787.

15) Sen I, Tamirisakandala S, Miracle DB, Ramamurty U. Microstructual effects on the mechanical behavior of B-modified Ti-6Al-4V alloys. Acta Mater 2007; 55: 49834993.

16) Asgharnia MK, Brantley WA. Comparison of bending and tension tests for orthodontic wires. Am J Orthod 1986; 89: 228-236. 
17) Walker MP, Ries D, Kula K, Ellis M, Fricke B. Mechanical properties and surface characterization of beta titanium and stainless steel orthodontic wires following topical fluoride treatment. Angle Orthod 2007; 77: 342-348.

18) AlcockJP, Barbour ME, Sandy JR, IrelandAJ. Nanoindentation of orthodontic archwires: The effect of decontamination and clinical use on hardness, elastic modulus and surface roughness. Dent Mater 2009; 25: 1039-1043.

19) Ren Y, Maltha JC, Kuijpers-Jagtman AM. Optimum force magnitude for orthodontic tooth movement: A systematic literature review. Angle Orthod 2003; 73: 86-92.

20) Proffit WR. Mechanical principles in orthodontic force control. In: Proffit WR, Fields HW, Sarver DM, editors. Contemporary Orthodontics. St. Louis, Mosby Elsevier; 2007. p.359-394. 